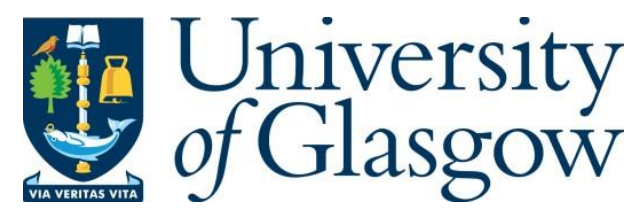

Chapman, C. and Ainscow, M. (2019) Using research to promote equity within education systems: possibilities and barriers. British Educational Research Journal, 45(5), pp. 899-917.

This is the peer reviewed version of the following article, Chapman, C. and Ainscow, M. (2019) Using research to promote equity within education systems: possibilities and barriers. British Educational Research Journal, 45(5), pp. 899-917, which has been published in final form at http://dx.doi.org/10.1002/berj.3544

This article may be used for non-commercial purposes in accordance with Wiley Terms and Conditions for Self-Archiving.

http://eprints.gla.ac.uk/187448/

Deposited on: 22 July 2019

Enlighten - Research publications by members of the University of Glasgow http://eprints.gla.ac.uk 


\title{
Using research to promote equity within education systems: possibilities and barriers
}

\author{
Christopher Chapman \\ Policy Scotland, University of Glasgow, G12 8RS
}

and

Mel Ainscow

University of Manchester, M13 9PU

\section{Introduction}

Achieving sustainable improvement in schools serving learners from disadvantaged communities is a major challenge facing countries around the world (e.g. OECD, 2012; UNESCO, 2015). This also has considerable implications for those of us in the research community as we seek to influence developments in the field. Put simply, how can our work be used to inform efforts to address the equity policy challenge?

The belief that research can have direct effects in the field has now largely been abandoned, even though it may still be held by some researchers, who, it has been suggested, 'seem surprised or even dismayed that their work is not immediately adopted into policy or practice' (Levin, 2011: 17). Drawing on our privileged positions as researchers closely involved in three large-scale national reform programmes in the United Kingdom, in this paper we offer advice on how research and, indeed, researchers can best contribute to improvements in the field. In so doing, we argue that education systems will only be able to use research effectively if steps are taken to overcome locally specific social, political and cultural barriers. As we will explain, this analysis has implications for policymakers, practitioners and, indeed, for those of us working in the world of academic research.

\section{Research and policy making}

Much has been written about the relationship between research and policy, some of which has focused on the quality of educational research itself. For example, over a decade years ago, Whitty (2006) summarised what he saw as the 'abuse of educational research'. While much has changed in the UK since this was written, many of these perceptions remain as strong as ever. However, for the purposes of this paper we put issues about the quality of the research to one side in order to focus on the relationship between research and policymaking.

Much of the literature sets up divisions between those involved in the production of research and those involved in the construction of policies in public services (e.g. Innvaer et al., 2002). In contrast to this polarised position, Smith (2013, p 38-39) offers five contrasting ways of conceptualising the relationship between research and policy. 
While these relate specifically to public health, they seem to hold true for broader public policy. The five conceptualisations are as follows:

1. Technocratic and instrumental: Whilst research should be one of the key factors influencing policy-makers, politics often gets in the way. This means that, in order to improve impact, researchers need to develop better relationships with policy-makers and must produce policy-relevant findings.

2. Complex and messy: Although many factors influence policy-making, relatively small factors can sometimes lead to significant changes. Chance can also play a significant role. Therefore, researchers who want to have impact need to work as policy entrepreneurs, promoting solutions to appropriate audiences and adapting solutions to exploit emergent policy windows.

3. Normative, political and interest-based: Policy decisions are often the result of political ideologies and interests. Whilst research findings may play a role in influencing ideology, they are rarely adopted unless they fit with established positions. By developing closer relationships with policymakers, researchers can increase the impact of their research but only when it supports the dominant ideological discourse.

4. Democratic and conceptual: Public perceptions and values influence policy decisions and research cumulatively over long time-frames. Therefore, whilst research may occasionally influence research directly, the more common influence is through contributing knowledge that shifts conceptualisations of particular issues. This highlights the importance of sensitivity regarding concepts, language and discourses.

5. Constructivist and sociological: The relationship between research and policy is a 'multi-directional interplay' Here, language and discourse are again important, particularly as the knowledge exchanged is translated and transformed as it moves between actors. It is therefore helpful to think about ideas, rather than evidence, as the unit of analysis.

These five conceptualisations are underpinned by social, political and cultural factors which act as facilitators and/or barriers for efforts to influence policy-making. Any system may hold elements of each of them at any one time, although the blend may vary both over time, and between different teams and units within a given context. This suggests that, in order for research to influence policy, researchers are likely to require a sophisticated understanding of the policy landscape, and a range of tools and approaches to ensure that evidence influences decisions. Furthermore, it is important to recognise that policy is made at all levels of a system, not least at the level of the classroom.

\section{Influencing policy-making in education}

With regard to education policy making, the uptake of research findings still remains limited. For example, Harris and colleagues (2013) argue that despite a valid 
knowledge base about what works and why at classroom, school and increasingly system levels, policy-making communities have been reluctant to engage with research findings and when they have this has tended to be selective. This can lead to situations where political ideology, anecdote and, on occasion, whim dominate policy-making. This suggests that there is a need for strong relationships between researchers and policy-makers, plus fluidity of movement of researchers into and out of government positions similar to the processes described in this paper.

Levin (2011) provides a helpful practical model to consider how knowledge mobilisation occurs, using three interconnected contexts: production, use and mediation. These contexts are not necessarily structures. Rather, they are better thought of as functions, with some people, organisations or groups operating in one or more of the contexts. Those that move between research-policy communities operate across all three contexts in order to span the boundary between research and policy communities. Sullivan and Skeltcher (2002) refer to these individuals as 'reticulists' who build capacity and collaborative practices to enhance their influence. They tend to be:

- Skilled communicators - with the ability to adapt their language to specific settings and empathise with others through negotiation and seeing a situation from a range of perspectives.

- Excellent networkers - gaining access to a range of settings, seeking out and connecting with others with common interests and goals

- Strategic in orientation - they see the 'big picture' and understand how different partners can contribute to achieve common goals

- Contextually astute - they understand how opportunities and constraints within the organisation can influence individual's behaviour

- Problem-solvers - they think laterally and creatively to seek solutions to the challenges they face.

- Self-managing - they take risks within a framework that understands organisational capacity. In this sense they have sound organisational skills.

Even with such qualities, the challenge of knowledge mobilization remains a complex process involving varied influences. A sense of what this can mean is well illustrated by David Laws, a former Schools' Minister in the UK Government, who commented:

'A lot of decision-making is not based on evidence but on hunch. I had little coming to me from civil servants that presented the latest academic evidence. Too often, they just serve up practical advice about how the minister can do what he or she wants. But politicians are prone to make decisions based on ideology and personal experience,' 1

This highlights graphically some of the challenges faced by researchers working in the spaces between research and policy-making communities. With this in mind, in what follows we reflect on our combined experiences of attempting to navigate this space in three education systems.

${ }^{1}$ The Guardian, $1^{\text {st }}$ August 2017 


\section{Generating data}

The argument we develop draws on our 'insider' involvement as researchers employed as advisers within three related improvement initiatives in different parts of the United Kingdom: City Challenge in England (2003-11), Schools Challenge Cymru in Wales (2014-17), and the Scottish Attainment Challenge (2015-19) ${ }^{2}$. Each of these projects has had a strong government mandate and massive financial investments. Whilst we were not both directly involved in each of these developments, throughout their existence we acted as critical friends to one another as we worked individually in one or more of the contexts. In this way, we have been able to share experiences, provide mutual support, and explore how research evidence and processes might help in moving things forward.

To varying degrees, the three projects each adopted an overall 'development and research' approach (Ainscow et al, 2012). This is one of a family of methodologies referred to by Fishman et al (2013) as 'design-based implementation research'. They aim to transcend traditional research/practice barriers in order to facilitate the design of educational interventions that are 'effective, sustainable, and scalable'. This is seen as occurring when researcher and practitioner knowledge meet in particular sites, aimed at producing new knowledge about ways in which broad values might better be realized in future practice.

Our involvement in the projects was as advisers working on a part-time basis. This points to a rather obvious methodological challenge regarding the analysis we provide. As researchers, we were given remarkable opportunities to put into practice ideas that had emerged from many years of investigating ways of developing more equitable schools and education systems. At the same time, we were provided with privileged access to information about how decisions are made within a national education system. On the other hand, as people charged with the task of championing the projects, how far can our interpretations be trusted, not least because efforts to collect data about the processes involved were mainly carried out in an incidental way?

This methodological challenge is addressed in the paper by triangulating the evidence we collected with data generated through independent evaluations of the initiatives. First, it is based on an analysis of our archive of documents that record the development of the projects, including observation notes and records of meetings with stakeholders. Secondly, a set of data is drawn from independent evaluations commissioned by governments. These studies provide an analysis of statistics that track the progress of students on national tests. In some instances, they have also generated qualitative data collected through surveys of staff in schools, plus interviews with samples of stakeholders, including students, politicians, national and local administrators, advisers and school leaders.

The accounts presented also draw on records of our many discussions with those involved in the initiatives, as well as evidence collected more directly through policy documents, statistical data, informal observations and interviews with participants. As we have indicated, our involvement placed us in a position of having privileged access to information regarding the way decisions are made within an education system, from

\footnotetext{
${ }^{2}$ See Ainscow, Chapman \& Hadfield (2019) for more detailed accounts of these initiatives.
} 
the levels of government ministers and senior civil servants, through to that of teachers in the classroom. All of this provided frequent reminders of the cultural, social and political complexities involved when trying to bring about changes in the way that an education system does its business.

\section{The Challenges}

Although each of the Challenge programmes had its own design, they do share a similar overall strategy. In particular, they each sought to explore new, more fruitful working relationships: between national and local government; between administrators and practitioners; within and between schools; and between schools and their local communities. A useful theoretical interpretation that can be made of these strategies is that they have sought to strengthen social capital, a factor that is known to be a feature of education systems that are more able to foster greater equity (Payne, 2008; Putman, 2000). In other words, they sought to facilitate relationships across different levels of their system and establish new pathways through which energy, expertise and lessons from innovations could spread. At the same time, the greater awareness of what was happening elsewhere often challenged expectations as to what is possible, particularly with regard to the progress of students from economically disadvantaged backgrounds.

The use of this approach was influenced by our earlier research that placed an emphasis on mutual critique, within and between schools, based on an engagement with shared data (Ainscow et al, 2006 and 2012). This, in turn, requires strong collective commitment from senior school staff and a willingness to share responsibility for system reform (Chapman, 2008).

In what follows, brief chronological accounts are provided of each of the initiatives and the contexts in which they took place.

City Challenge in England. Launched in 2003 in London, the success of City Challenge has been widely reported, leading to extensive debates as to what were the key factors that led to its impact (e.g. Barrs et al, 2014; Claeys et al, 2014; Hutchings et al, 2012). As a result of their research into the implementation of London Challenge, Kidson and Norris (2014) conclude that it was a distinctive example of public service improvement that was practitioner-focused, highly collaborative and applied across a system. There are, however, a range of other views as to what made the difference in London. In a helpful summary of these positions, Lowe (2015) points out that other government interventions that took place around the same time may also have had an impact. Burgess (2014) introduces another perspective, suggesting that the basis for London's progress was the ethnic composition of its school population. In particular, he concludes that a key factor had been the attraction to London of migrants and others aspiring to a better life.

The first phase of City Challenge concentrated on the improvement of London secondary schools (Brighouse, 2007). By 2007, the national inspection agency, Ofsted, was reporting that standards in these schools had improved 'dramatically' and that the capital had recorded its best ever examination results, showing London's state school pupils leading the rest of the country for the third year running (Ainscow 2015). 
Drawing on the experiences of London, we were closely involved in the Greater Manchester Challenge, a follow-up initiative involving over 1,100 schools in ten local authorities, with a government investment of around £50million (see Ainscow, 2015, for a detailed account of this initiative). The decision to invest this large amount reflected a concern regarding educational standards in the city region, particularly amongst children and young people from disadvantaged backgrounds. It is important to note at this stage, too, that both the London and Greater Manchester Challenge programmes each had the active involvement of a Government Minister. In terms of the impact, the presence of this form of high-status political leadership should not be overlooked.

A detailed analysis of the context led to the conclusion that plenty of good practice existed across Greater Manchester schools. Consequently, it was decided that collaboration and networking would be the key strategies for strengthening the overall capacity of the system to reach out to vulnerable groups. More specifically this involved a series of inter-connected activities for 'moving knowledge around' in order to build a self-improving school system (Ainscow, 2012). These were much influenced by the findings of earlier research we had carried out with colleagues (e.g. Ainscow, \& West, 2006; Chapman, 2008)

With this in mind, Families of Schools were set up. This approach partnered schools that serve similar populations whilst, at the same time, encouraging partnerships amongst schools that were not in direct competition with one another because they did not serve the same neighbourhoods. Led by head teachers, the Families of Schools proved to be successful in strengthening collaborative processes within the city region, although the impact was varied.

In terms of schools working in the most disadvantaged contexts, more intensive school partnerships were found to be the most powerful means of fostering improvements (Hutchings et al., 2012). Most notably, what was called the Keys to Success programme led to striking improvements in the performance of some 200 Greater Manchester schools facing the most challenging circumstances. A common feature of almost all of these interventions was that progress was achieved through carefully matched pairings (or, sometimes, trios) of schools that, once again, cut across social 'boundaries' of various kinds, including those that separate schools that are in different local authorities (Ainscow, 2013). In this way, expertise that was previously trapped in particular contexts was made more widely available.

Another effective strategy to facilitate the movement of expertise was provided through the creation of various types of hub schools. So, for example, some of the hubs provided support for other schools regarding ways of supporting students with English as an additional language. Similarly, so-called 'teaching schools'3 providing professional development programmes focused on bringing about improvements in classroom practice.

It is worth adding that another key factor in the success of both the London and Greater Manchester Challenge programmes was the involvement of teams of expert

\footnotetext{
${ }^{3}$ The idea of teaching schools, which act as professional development hubs, has subsequently became part of national policy in England.
} 
advisers. Chosen because of a track record of leading successful school improvement, they were given the mandate and resources to intervene in schools, helping them to develop, implement and monitor the impact of their own improvement plans.

An independent evaluation of the City Challenge programme concluded that it had been largely successful in achieving its objectives (Hutchings et al, 2012). Commenting on this, the authors of the report argue:

Clearly a great many factors contributed to these improvements, including national policies and strategies and the considerable efforts of head teachers and staff. However, these factors apply everywhere in the country. The most plausible explanation for the greater improvement in Challenge areas is that the City Challenge programme was responsible. The vast majority of stakeholders at all levels who contributed to this evaluation attributed the additional improvements that have been made in these areas to the work of City Challenge (p.vi).

The evaluators also concluded that the strategic factors contributing to its success were the timescale; the focus on specific urban areas; flexibility of approach; use of expert advisers and bespoke solutions; school staff learning from practice in other schools; and the programme ethos of trust, support and encouragement.

Schools Challenge Cymru. Wales shares a close political and social history with the rest of Great Britain, and almost everyone speaks English. However, the country has retained a distinct cultural identity and is officially bilingual, with Welsh being spoken by about $20 \%$ of the population, mostly in the north and west of the country. Although it is part of the United Kingdom, Wales has a form of self-government created in 1998 following a referendum and has its own education policies. There are also 22 local authorities responsible for a range of public services, including education.

Like many school systems that are seen to be successful (e.g. Alberta, Finland, Singapore), Wales is small, with about 3.1 million inhabitants. Despite its size, however, the performance of the school system has been a cause for concern, particularly in terms of outcomes for learners from low-income families, as noted in a country review conducted by OECD (2014). Most significantly, the review argued that whilst the pace of reform in recent years has been high, it has lacked a long-term vision, an adequate school improvement infrastructure, and a clear implementation strategy that all stakeholders share.

The review noted that the system has many strengths to build on, not least its inclusiveness, before going on to suggest a number of concrete policy options that would strengthen it over the long term. In particular, it argued for the development a long-term vision, translated into measurable objectives. With this in mind, in 2014 the Welsh government instigated a five-year reform plan for the education of 3-19 year old learners in the document 'Qualified for Life'. This provides a timeline for key activities and identifies immediate measures to be taken. One of these was the introduction of Schools Challenge Cymru. 
Launched in 2014, the purpose of the initiative was to accelerate progress across the Welsh education system (Ainscow, 2016). More specifically, it aimed to: bring about rapid improvements in the performance of schools serving the more disadvantaged communities; and use lessons from these developments to strengthen the capacity of the education system to improve itself. The budget was approximately 20 million pounds per year.

Building on the earlier experiences in London and Greater Manchester, the Welsh initiative worked initially with 40 secondary schools serving disadvantaged communities (designated as the 'Pathways to Success') and their local primary school partners. Similar to City Challenge, a team of advisers were involved in supporting these schools. In addition, a small group of champions advised on the overall strategic direction of the initiative.

The advisers and champions were directly accountable to the Minister for Education and Skills. As was the case in City Challenge, the Minister was closely associated with the initiative, visiting each of the schools at least twice over the first 18 months. This provided the political mandate that Claeys et al (2014) argue is essential to change strategies that mainly emphasise bottom-up action.

In summary, the results over the first two years showed that overall attainment in the GCSE examinations taken by almost all students at the age of 16 , across the Pathways to Success schools, improved by 7.0 percentage points, with $87 \%$ of the schools securing improvements in this measure. This rate of improvement was faster than the overall progress made across Wales over the same period. The attainment of students entitled to free school meals ${ }^{4}$ across the schools improved by 8.2 percentage points, with $74 \%$ of the schools securing improvements.

In making sense of these trends, it is important to remember that the participating schools were chosen because of the challenges they face and the fact that they had, to varying degrees, performed poorly over many years. Many of them became striking examples of what is possible when the expertise and energy within schools are mobilised. It should be noted, however, that these gains were hard won, and may remain fragile without continuing support.

Moving beyond the 40 schools, there was evidence too that Schools Challenge Cymru began to have a ripple effect across the education system in ways that have raised expectations regarding how rapidly improvements can be achieved (Hadfield \& Ainscow, 2018). This has particular implications for efforts to improve outcomes for learners from low-income families, where low expectations can be a factor in preventing their progress (Kerr \& West, 2010).

An independent evaluation of Schools Challenge Cymru (Carr, Brown \& Morris, 2017) concluded that the quality of leadership and management had improved in the majority of Pathways to Success schools. In two-fifths of the schools, involvement in the programme were considered to be largely, or wholly, responsible for the changes in pupil engagement, with schools recruiting support staff as central to their approach to improving pupil engagement. Some schools were optimistic about the sustainability of

\footnotetext{
${ }^{4}$ An indication of economic disadvantage
} 
perceived improvements in pupil attendance, hoping to ensure that good attendance became the norm. The report also concluded that the programme had contributed both to the strengthening of professional development within the schools and, in some cases, extended it.

The Scottish Attainment Challenge. Responsibility for education is fully devolved to Scottish government and is administrated through 32 local authorities that have the legal responsibility for ensuring the quality of provision. Scotland has approximately 5.3 million and there are around 2,500 schools within the system. $96 \%$ of the population is educated in public funded local authority managed schools. The system performs above OECD averages but saw a relative decline in performance in PISA 2016.

The current administration is committed to improving educational 'excellence and equity'. In March 2013, the then Cabinet Secretary for Education and Lifelong Learning announced six new policy priorities to tackle educational inequity: school partnerships; class sizes and teacher numbers; use of data to drive improvement; parental involvement; leadership; and innovation. This announcement provided the opportunity to design and implement the School Improvement Partnership Progamme (Chapman et al., 2015; 2016) and the Government's own Raising Achievement for All initiative. These programmes, combined with some of the lessons learned from Challenge type interventions in the other systems, provided a foundation and catalyst for the Scottish Attainment Challenge. Commenting on this, the First Minister stated:

"It is important we learn not just from good practice here in Scotland, but also from elsewhere in the UK and overseas, to find ways of working that have the greatest impact. I have been particularly impressed with the results of the London Challenge in transforming school performance in that city and so, while not all of it will be appropriate to Scottish circumstances, we will draw heavily on it in developing our own Attainment Challenge."

(First Minister February 2015) ${ }^{5}$

The Scottish Attainment Challenge was launched in February 2015, with high levels of political commitment. Later, in 2016, prior to the Scottish Parliament elections, the First Minister went on to commit her own political reputation to closing and ultimately eliminating the attainment gap.

The Challenge was backed by a $£ 100 \mathrm{~m}$ fund to support improvements in attainment over a four-year period in seven 'Challenge Authorities'. At the same time, an acknowledgment that not all children in poverty lived in areas of high concentrations of disadvantage led to Government to include in the strategy 57 primary schools serving the most disadvantaged children outside of the Challenge Authorities. This involved the allocation of a further $£ 2.5$ million across a further 14 local authorities. All Challenge Authorities and schools involved in the Programme construct annual action plans which bid for additional resource from the Attainment Fund. These plans are reviewed by Education Scotland and Scottish Government who either approve seek revisions to the plans.

\footnotetext{
${ }^{5}$ https://news.gov.scot/news/smart-money-on-attainment
} 
Drawing on the experiences of England and Wales, a team of attainment advisors were identified to provide support and challenge the system on a full or part-time basis. They worked in their respective authorities but reported to Scottish Government rather than to the local education authority. As yet, there is no credible independent evaluation assessing the impact of the programme.

In May 2016, the Attainment Fund was increased over the five years to 2021-22. This involved the schools programme being extended to 133 secondary schools within nine Challenge Authorities and another 28 secondary schools, in eleven other authorities. Meanwhile, from April 2017, the Government provided £1,200 for every child from the most disadvantaged backgrounds (using registration for free school meals as the proxy indicator) in the form of the Pupil Equity Fund (PEF). This is allocated directly to schools, rather than using the traditional system of allocating resources through local authorities. In practice, this means that some primary schools serving the most disadvantaged communities are receiving extremely high levels of additional funding. For example, over the four-year period, a primary school in Glasgow will receive in excess of $£ 1.2 \mathrm{~m}$.

These recent developments have not been without controversy. Debate about using the place-based indicator of Scottish Index of Multiple Deprivation as criteria for inclusion in the programme continues. For example, Patterson (2018) argues that two thirds of deprived children are not in deprived areas and that one-quarter of children living in deprived areas are not educationally deprived. Issues have also been raised about entitlement to free school meals as a reliable proxy indicator for poverty. The introduction of PEF has also had a mixed response. Some head teachers have welcomed the additional responsibility and autonomy, while others have been more sceptical about their own, and the system's ability to use the resource wisely, leading to concerns over impact and value for money. Within a context of severe cuts in public service funding, particularly to local authorities, some stakeholders view the decision as an attempt to redistribute resources, and, in doing so, both disempower local authorities and move the spend to nearer the front line where some argue it is more likely to have more impact. Local authorities have responded to PEF in a number of ways which has created a wide variation in local practices. For example, in some authorities, the schools' plans for PEF are reviewed and 'approved', thus maintaining local control of the spend. Others have respected the policy intention and taken a much lighter touch approach.

There is also an ongoing tension between allocating resources to the Challenge programme and putting appropriate monitoring procedures in place to ensure the funds are used wisely. At times, ideas and intentions have been bold and innovative but the system has not had the personnel or capacity to meet the aspiration. In some cases, this has led to significant underspend.

\section{Making sense of the barriers}

A common feature of the three initiatives we have described is the emphasis they place on bottom-up leadership within a context of top-down political mandate. As we have seen, evidence from research has been used to inform these developments to a considerable degree. However, we have found that injecting ideas from research into such developments has sometimes been difficult because of a series of interconnected barriers. Broadly stated, these relate to: 
- Social factors, including the extent to which relationships exist that encourage the sharing of expertise though mutual support and challenge;

- Political factors, due to the impact of the attitudes and preferences of key partners; and

- Cultural factors, created by local traditions and the expectations of those involved as to what is possible.

In what follows we reflect on our involvement in the three projects to make sense of these barriers.

Social factors. Our experiences in the three initiatives underline the way relationships between key players have a significant role in helping to foster or inhibit the efforts of researchers to contribute to planning and decision making. Beyond saying this, it is difficult to make generalisations, since each set of relationships relates to particular contexts and circumstances.

In reflecting further on our experiences, however, it does seem that 'size matters'. To give a striking example, one of us contributed to planning in a very small rural district, where there were concerns about poor standards in the schools. To an outsider with lots of urban experience, the closeness of the links between head teachers in this community seemed to be a positive feature in terms of the encouragement of greater collaboration.

In line with the thinking developed in this paper, we encouraged a restructuring that would enable existing good practices within local schools to be made available to more students and encourage joint practice development. This was to be achieved through the strengthening of various forms of cooperation between the schools. This required new roles for head teachers, some of whom volunteered to take on the task of leading these developments. With this in mind, we consulted with all the heads within the authority. As a result, a new momentum for change quickly emerged in the primary sector, where a group of five relatively successful head teachers took the initiative in moving things forward.

In discussing their roles, these heads commented on the social complexities they faced in getting colleagues to cooperate. In particular, they commented on the implications of the fact that amongst schools in a small community 'everybody knows one another'. They explained that relationships were usually warm and cordial, something that we certainly experienced. However, it was also apparent that this closeness between colleagues had the potential to create barriers to genuine collaboration between schools. One headteacher summed this when she said, 'we don't bare our souls around here'. In other words, if you have a problem in your school, you keep it to yourself. Clearly, such a social climate can make it difficult for colleagues to support one another. It also means that the external researcher - there to support and advise - faces what may well be hidden barriers to an understanding of the dynamics of the local school system.

It follows that the involvement of a researcher acting in the role of adviser requires the fostering of constructive relationships with key partners. We have found that maintaining such relationships creates many dilemmas that usually have to be 
addressed on the spot, as they occur. For example, a meeting was held with senior officers in one local authority where we were concerned about the poor quality of support provided for primary schools. At times the meeting became heated, as authority staff attempted to challenge our analysis and one colleague, in particular, was clearly distressed. Indeed, at one point he explained that he had never felt so personally humiliated during his long professional career. This particular meeting did not lead to an immediate outcome that could be described as being positive. Nevertheless, we felt that it was necessary to intervene in a context where thinking and practices were limiting opportunities for children. Subsequently, a series of further meetings did lead to agreement as to necessary actions to strengthen the work of this particular local authority in supporting its schools.

In reflecting on incidents such as this one, we were occasionally reminded of Robert Bales' theory of group systems that we had used in earlier research (see Ainscow, Hargreaves \& Hopkins, 1995). As Bales predicts, attempts to get different stakeholders to pull together leads to tensions between the need to establish cohesion amongst groups, whilst, at the same time, taking actions to achieve our goals. Put simply, it is relatively easy to maintain cooperation until the moments when hard decisions had to be made, most particularly regarding the setting of priorities and the allocation of resources.

Political factors. The most striking evidence of the political nature of large-scale system change projects occurred in two of the countries following national elections. This led to new ministers being appointed and, as a result, the Challenge projects losing much of their political mandate. The projects did continue, however, although with less power to make things happen. Having said that, in the case of one of the initiatives, we have recent empirical evidence of the continuing impact of its legacy five years later, most strikingly in terms of partnerships and networks (Armstrong \& Ainscow, 2018).

The three Challenge programmes emerged during an unprecedented period of change within their education systems, not least in terms of decision-making regarding education policy. The ways in which decisions were made regarding changes varied across the three countries. England was in the process of giving schools much greater autonomy, not least regarding the use of financial resources and the appointment of staff members. This was also leading to a much greater role for head teachers as system leaders, working together to coordinate collaborative improvement efforts. In all three contexts the role of the local authority in relation to the management of the school system is being questioned and, in this case, has massively reduced over the past three decades (Salokangas \& Ainscow, 2017).

Meanwhile, the other two countries continued in a much more centralised way, with decision mainly shared between the national government and local authority levels. As we have noted, there was evidence of continuing tensions between these two levels regarding policies, not least in respect to the determination of priorities and the use of resources. All of this provides further difficulties for researchers as they navigate the system, trying to advise on policy developments.

During the setting up phases of the three programmes, much use was made by government officials of the term 'partnership' in describing what was to happen. We 
sensed that for some local authority colleagues this was a source of irritation, in that the decisions to have the initiatives were largely imposed by national government in what were clearly seen as processes of intervention in areas of concern or disadvantage.

One of the factors that was behind these tensions were different views as to what needed to happen in order to improve education systems: put bluntly, a difference between those who believe in locally led development and others who continue to adopt a centralising perspective. For example, the latter view was starkly expressed in an email note sent to colleagues within the DfES in London during the City Challenge period, which stated that, as far as improving attainment amongst disadvantaged students was concerned, 'the strategy must be exactly the same, whether it is in Plymouth (in the south west of England), or in Sunderland (in the far north east)'. The implication being we know what to do; it just needs to be done irrespective of context.

This instinct to direct from the centre kept surfacing at meetings of challenge/attainment advisers, when civil servant colleagues took opportunities to brief the groups on the latest proposals from central government and the necessity for reporting back to central government through complex reporting mechanisms. In general, the teams found these inputs helpful in the sense that they made them feel ahead of the game regarding policy decisions, while the bureaucratic reporting and accountability systems were perceived to be frustrating and heavy handed. In these cases, our concern was that, too often, they gave the wrong message in respect to the theory of change we had adopted.

A striking example of this, that created a significant distraction, was as a result of the publication of a White Paper about the reform of one of the three national systems. The civil servant who led on this initiative as far as primary schools was concerned became particularly dogged in her efforts to impose a centrally determined strategy on the schools. With this in mind, for some months she guided the agenda of the team of primary advisers in a direction that, from our point of view, represented a significant deviation to the rationale we had developed together. During this phase, our own involvement in decision making was clearly marginalised

Sustainability was a major concern in all three initiatives. The history of large-scale, heavily funded improvement projects is that, even when they are seen to be initially successful, the impact gradually fades once the additional resources are taken away (Ainscow, 2015). As Scotland moves into the second half of the planned period of funding, questions about sustaining levels of activity beyond the funding period are beginning to emerge, with some Challenge Authorities suggesting that they cannot sustain their commitments beyond the duration of the programme.

One way of addressing this problem is to strengthen the so-called middle tier - that is to say, the administrative arrangements that are intended to coordinate the development of education provision within a local area. In Wales, for example, this means the 22 local authorities, which are grouped together in four regional consortia that are intended to support school improvement efforts. At the time of writing, the establishment of six Regional Improvement Collaboratives mean that Scotland is moving in a similar direction. There are, however, potential barriers to making such 
regional partnerships work, including the large geographical areas that they sometimes cover, competing philosophies and educational agendas, and the struggles they can create regarding decision making across political boundaries.

Within national systems that continue to emphasise top-down accountability, the responses of local authorities can also, at times, act as a barrier to school-level innovation. For example, one very experienced head teacher, appointed to improve a school in difficulty, talked about local authority officers frequently commenting negatively regarding the ways he deals with minor administrative matters.

Cultural factors. In all three countries, the efforts to inject greater pace into the improvement of schools drew attention to the untapped potential that exists within schools. They also threw light on the factors that have limited the impact of earlier efforts to mobilise this potential. Our monitoring suggests that these barriers mainly relate to existing ways of working, which, although well intended, consume time and resources, and delay action in the field. One head teacher echoed the views of many others when he commented that, in his part of the world, school improvement is like trying to drive more quickly down a road with speed bumps every few yards.

The experience of the three programmes suggests that many of the 'bumps' relate to existing ways of working, which reflect taken for granted assumptions as to what is possible. Although well intended, these traditions often consume time and resources, and delay action. They include, for example, the over emphasis placed by some local authorities on putting schools, particularly those facing challenging circumstances, under unnecessary pressure. This tends to demoralise the key agents of change, i.e. the staff in the schools. It can also lead to considerable time being wasted on debating and disputing plans and targets. Our experience is that, whilst plans and target setting can be helpful, without powerful support strategies they are unlikely to lead to sustainable change.

Linked to this are actions by some local authority staff that limit the freedom of school leaders to take responsibility for their own improvement. In particular, we found that there were often what seemed to be multiple reporting arrangements, such that school leaders were spending too much time preparing reports for different audiences, attending various review and scrutiny meetings, and being given different (and at times conflicting) advice on the improvements required and how they can be achieved. Despite calls for the empowerment of schools and headteachers this can lead to a sense of dependency on outsiders to lead improvement efforts, rather than those in schools taking responsibility and being accountable for improved outcomes. In such situations, school leaders can feel undermined and disempowered. As a result, they tend to make poor decisions, and therefore find it more difficult to prioritise their improvement strategies.

In addressing these barriers, efforts are needed to clarify the respective roles of local authorities. Specifically, this requires local authority staff to know, trust and support their schools, alongside providing appropriate encouragement to improve. These changes in roles and responsibilities are likely to be particularly challenging during periods of transition, whilst more locally led improvement strategies are developing, but they are a matter of urgency in order that rapid progress can be achieved. 
There are also barriers related to the uncertainly that exists within governments regarding the stance that is needed to support the development of locally driven collaborative improvement. In particular, it must be recognised that the use of the power of collaboration as a means of achieving both excellence and equity in schools requires an approach to national policy implementation that fosters greater flexibility at the local level, in order for practitioners to have the space to analyse their particular circumstances and determine priorities accordingly. This means that policy makers must understand that the details of policy implementation are not amenable to central regulation. Rather, these have to be dealt with by those who are close to and, therefore, better positioned to understand local contexts.

\section{Drawing out the lessons}

Together, the experience of these three Challenge programmes lead us to suggest a strategic framework that can be used to think about how school systems can be supported to make better use of available knowledge. In particular, it has the potential to create new spaces within which academic researchers can become partners in the process of improvement, adding their expertise to that which exists within a school system.

In summary, the framework involves the following interconnected ideas:

- A shared understanding of overall purposes. Some of the difficulties we have reported had their origins in a lack of agreement as to what should be the intended outcomes. Given that change requires coordinated efforts across the different levels of an education system, an agreed and clear purpose is an essential condition. Reaching the required degree of clarity is both a cultural and political process in which certain voices might be excluded, whilst others are over privileged, and in which underpinning assumptions need to be challenged

- On-going contextual analysis of a system's existing capacity for collaborative improvement. This has to be capable of providing a deeper analysis of the barriers that are limiting progress. At the same time, it should identify areas of promising practice, drawing out key learning and applying this to the development of the necessary human and social capital to support system level improvement efforts. It is important that this analysis operates at different levels of the system.

- Brokerage that crosses professional and social boundaries, within schools and across networks. This is in order to increase exposure to various sources of expertise and innovative practice. It requires the orchestration of different forms of individual and organisational networks into integrated sub-systems capable of fostering system level improvements, even in challenging circumstances.

- The development of capacity for leadership at all levels of a system. This must be capable of leading collaborative learning within and between schools, and with the wider community. It requires the micro-mobilisation of successful senior staff members to take on system leadership roles, in combination with the macro-mobilisation of sufficient school leaders at all 
levels to create a professional movement with sufficient momentum to overcome internal and external resistance.

- The creation and maintenance of a strong political mandate at the national and local levels. This is necessary in order to create the conditions within the system that are supportive of collaborative local action. It requires new thinking, attitudes and relationships across education systems. It also means that inequalities of power between elements of the system are addressed.

What connects these design principles in a way that makes them coherent is the way they focus attention on the importance of managing and interconnecting individual, organisational and system level learning, within complex transitional dynamics. These learning processes help to make the familiar unfamiliar in ways that challenge expectations as to what is possible, whilst, at the same time, drawing attention to examples of different ways of working that can act as the focus of joint practice development. In such contexts, the presence of researchers - acting as critical friends, drawing attention to relevant research evidence from elsewhere, and advising how processes of inquiry can be built into strategies that are trialled - can make significant contributions.

\section{Conclusion}

The accounts of our involvement in the three projects point to ways in which the barriers we have identified can be overcome in order that research can be helpful in promoting change. By and large, these responses are not based on a technicalrationale process through which research-based knowledge is presented to practitioners in the hope that this will then be used to guide decision-making and action. Rather, they involve a rather messy social learning process, within which researcher expertise and perspectives are brought together with the knowledge of policy makers and practitioners. Where this works, it can lead to the development of new, context-specific knowledge that can support change processes.

The implication is that successful change requires the coming together of different perspectives and experiences in a process of social learning and knowledge creation within particular settings. Researchers who get involved in such processes must expect to face many dilemmas. Consequently, they have to develop new skills in creating collaborative partnerships that cross borders between actors who have different professional experiences. They also need to mobilise personal support in dealing with the pressures this involves, not least the nagging concern that we are dancing with the devil.

In the paper, we have illustrated how the different roles and socio-cultural contexts of policy-makers/practitioners and academics create a complex set of power relations, which have to be factored into the process of introducing ideas from research. This reveals how those who work in the field derive their power from being primary actors: they can cause things to happen or to cease to happen in a way that is denied to academics. Meanwhile, researchers derive their power from standing at a distance: they can problematize the actions of practitioners. 
At their most productive, these power relations lead to dialogue in which the academics' views are informed by the realities of practice, and practitioners' views change in response to 'outsider' critique. At their least productive, academics mistake their distant position for superiority, and claim moral and intellectual authority over practitioners; while practitioners dismiss academics as being unworldly and resist their critiques. Managing these relationships is crucial to the success of attempts to use research knowledge to guide policy and practice in the field.

\section{References}

Ainscow, M., (2012) Moving knowledge around: strategies for fostering equity within educational systems. Journal of Educational Change 13(3), 289-310

Ainscow, M. (2013) Developing more equitable education systems: reflections on a three-year improvement initiative. In V, Farnsworth and Y. Solomon (Eds.), What works in education? Bridging theory and practice in research. London: Routledge

Ainscow, M. (2015) Towards self-improving school systems: lessons from a city challenge. London: Routledge

Ainscow, M. (2016) Schools Challenge Cymru: A catalyst for change? Wales Journal of Education 1 (1), 6-22

Ainscow, M., Booth, T., Dyson, A., with Farrell, P., Frankham, J., Gallannaugh, F., Howes, A. \& Smith, R. (2006) Improving schools, developing inclusion. London: Routledge

Ainscow, M., Chapman, C. \& Hadfield, M. (2019) Changing education systems: a research-based approach. London: Routledge (in press)

Ainscow, M., Dyson, A., Goldrick, S. \& West, M. (2012) Developing Equitable Education Systems. London: Routledge

Ainscow, M. and Howes, A. (2007) Working together to improve urban secondary schools: a study of practice in one city. School Leadership and Management 27, 285300

Ainscow, M. and West, M. (eds.) (2006) Improving urban schools: Leadership and collaboration. Open University Press

Armstrong, P. and Ainscow, M. (2018) School-to-school support within a competitive education system: views from the inside. School Effectiveness and School Improvement, 29:4, 614-633

Barrs, S., Bernardes, E., Elwick, A., Malortie, A. McAleavy, T., Mclnerney, L., Menzies, L. and Rigall, A. (2014) Lessons from London schools: investigating the success. Reading: CfBT Trust 
Brighouse, T. (2007) The London Challenge - a personal view. In T. Brighouse and L. Fullick (eds.) Education in a global city. London: Institute of Education Bedford Way Papers

Fishman et al (2013) Design-Based Implementation Research: An Emerging Model for Transforming the Relationship of Research and Practice. National Society for the Study of Education, 112 (2), 136-156

Burgess, S. (2014) Understanding the success of London's Schools. Bristol: CMPO Working Paper No.14/333.

Carr, C., Brown, S. and Morris, M. (2017) Assessing the contribution of Schools Challenge Cymru to outcomes achieved by Pathways to Success schools. Cardiff: Welsh Government

Chapman, C (2008) Towards a framework for school-to-school networking in challenging circumstances, Educational Research, Vol. 50, No. 4, pp. 403-420

Chapman, C., Chestnutt, H., Friel, N., Hall, S. and Lowden, S. (2016) Professional capital and collaborative inquiry networks for educational equity and improvement? Journal of Professional Capital and Community, (1) 3, 178 - 197

Chapman, C., Lowden, K., Chestnutt, H.R., Hall, S., McKinney, S., Hulme, M. and Friel, N. (2015), The School Improvement Partnership Programme: using collaboration and inquiry to tackle educational inequity. Livingston: Education Scotland.

Chapman, C. and Muijs, D. (2014) Does school-to-school collaboration promote school improvement? A study of the impact of school federations on student outcomes. School Effectiveness and School Improvement, 25(3), pp. 351-393

Claeys, A., Kempton, J. \& Paterson, C. (2014) Regional challenges: a collaborative approach to improving education. London: CentreForum

Department for Education and Skills (2013) The future delivery of education services in Wales: Consultation document. Cardiff: Welsh Assembly.

Fishman et al (2013) Design-Based Implementation Research: An Emerging Model for Transforming the Relationship of Research and Practice. National Society for the Study of Education, 112 (2), 136-156

Hadfield, M. \& Ainscow, M. (2018) Inside a self-improving school system: collaboration, competition and transition. Journal of Educational Change, 19(4), 441462

Hargreaves, D. H. (2010) Creating a self-improving school system. Nottingham; National College for School Leadership

Harris, A., Chapman, C., Muijs, D. and Reynolds, R. (2013) Getting lost in translation: The problem of the limited international take-up of educational effectiveness research 
(EER), teacher effectiveness research (TER) and school/system improvement research (SSIR) by practitioners and policy makers. School Leadership and Management 33 (1) 3-20

Hopkins, D., Ainscow, M. and West, M. (1994) School improvement in an era of change. London: Cassell

Howard, J. (2005) Knowledge exchange networks in Australia's innovation system: overview and strategic analysis: report of a study commissioned by the Department of Education, Science and Training, DEST, Canberra.

Hutchings, M., Hollingworth, S., Mansaray, A., Rose, R. and Greenwood, C. (2012) Research report DFE-RR215: Evaluation of the City Challenge programme._London: Department for Education

Innvaer, S., Vist, G., Trommald, M. and Oxman, A (2002) Health policymakers' perceptions of their use of evidence: A systematic review, Journal of Health Services Research and Policy. (7) 4, 239-244

Kerr, K. and West, M. (Eds.) (2010) Insight 2: Social inequality: can schools narrow the gap? Macclesfield: British Education Research Association

Kidson, M. \& Norris, E. (2014) Implementing the London Challenge. London: Joseph Rowntree Foundation

Levin, B. (2011) Mobilising research knowledge in education. London Review of Education 9 (1), 15-26

Lowe, J. (2015) The London schools revolution: Something remarkable has happened in the capital's schools. Prospect, February 2015

Mitton, C., Adair, C.E., McKenzie, E., Patten, S.B. and Perry, B.W. (2007) Knowledge transfer and exchange: Review and synthesis of the literature. Milbank Quarterly, 85(4): 729-768.

OECD (2012) Equity and quality in education: supporting disadvantaged students and schools. Paris: OECD Publishing

OECD (2014) Improving schools in Wales: An OECD perspective. Paris. OECD

OECD (2016) Country Note: Programme for international student assessment (PISA) results from PISA 2015. Paris: OECD

Payne. C. M. (2008) So much reform, so little change: The persistence of failure in urban schools. Cambridge: Harvard Education Press

Putnam, R. D. (2000) Bowling alone. New York: Simon \& Schuster

Salokangas, M. and Ainscow, M. (2017) Inside the autonomous school: making sense of a global educational trend. London: Routledge 
Scottish Government (2018a) Evaluation of the Attainment Scotland Fund - interim report (Years 1 and 2) Edinburgh: Government Social Research. Accessed $4^{\text {th }}$ April 2018 at http://www.gov.scot/Resource/0053/00532725.pdf

Scottish Government (2018b) Annex: Qualitative Research for the evaluation of the Attainment Scotland Fund (Produced by Research Scotland) Edinburgh: Government Social Research. Accessed $4^{\text {th }}$ April 2018 at: http://www.gov.scot/Resource/0053/00532726.pdf

Smith, K. (2013) Beyond evidence-based policy in public health: the interplay of ideas. Basingstoke: PalgraveMacmillan

Sullivan, H. \& Skelcher, C. (2002). Collaborating across boundaries. London: Palgrave UNESCO (2015) Education for all 2000-2015: achievements and challenges. UNESCO: Paris

Whitty, G. (2006) Education(al) research and education policy making: is conflict inevitable? British Educational Research Journal 32 (2),159-176 